\title{
Uma breve história da felicidade na publicidade nacional (1960-2010)
}

Henrique Moreira Mazetti

\section{Resumo}

0 artigo tem o objetivo de apresentar e discutir as transformações nas representações de felicidade em anúncios publicitários veiculados nas revistas Veja e O Cruzeiro entre 1960 e 2010, com o intuito de refletir sobre os valores morais que informam o discurso publicitário nacional. Identificamos três momentos que marcam formas diferentes de representar a felicidade nos anúncios: 1) uma associação da vida feliz à experiência coletiva da família ou da nação; 2), uma aproximação da noção de vida plena à exibição de status social; 3) a sedimentação das relações entre felicidade e autoexpressão. Por fim, tais alterações são interpretadas a partir de trabalhos de autores como MacIntyre, Taylor e Lipovetsky.

\section{Palavras-Chave}

Publicidade. Felicidade. Moralidade.

Henrique Moreira Mazetti I mazetti@gmail.com Doutor em Comunicação e Cultura pela Universidade Federal do Rio de Janeiro - UFRJ, Brasil. Professor do Departamento de Comunicação Social da Universidade Federal de Viçosa - UFV, Brasil.

\section{Introdução}

Fortemente ancorada no senso comum, a associação entre publicidade e felicidade está longe de ser enganosa. Pelo contrário, a ideia de conquistar, experimentar e exibir uma vida feliz é um artifício empregado de inúmeras maneiras para se vender de sapatos a planos de saúde. A publicidade contemporânea convoca, sem pudores, um exército de rostos sorridentes para estampar os anúncios veiculados nos mais diversos meios de comunicação. Entretanto, as articulações entre publicidade e felicidade raramente são pensadas em uma perspectiva histórica. Um certo grau de inevitabilidade parece pairar sobre as faces felizes que nos convidam a comprar carros, móveis de cozinha e computadores. Todavia, nem sempre as peças publicitárias foram assim. Segundo Sant'anna (2010), até a década de 1920, a propaganda impressa era, em grande parte, "um cortejo de seres sofredores" (2010, p. 183). Antes que a saúde, a felicidade e 0 bem-estar ganhassem espaço no discurso publicitário, a exibição da tristeza, da doença e do sofrimento era comum nas mensagens comerciais. 
A constatação de que a publicidade nem sempre acionou a felicidade como argumento persuasivo permite questionar o percurso histórico que a noção assumiu em um discurso singular como o da publicidade. Se as peças publicitárias outrora demonstravam pouca aptidão para privilegiar a vida feliz, pequenas são as garantias de que as concepções de felicidade empregadas pelos anúncios permaneceram estáveis ao longo dos anos. Identificar as mutações nos modos como a felicidade foi exibida pela publicidade nas últimas décadas abre, assim, uma interessante possibilidade de questionar as transformações da moralidade que sustenta 0 discurso publicitário e, ao mesmo tempo, demonstrar a singularidade dos nossos modos contemporâneos de pensar a vida feliz. Foi a partir dessa visada, e em diálogo com os trabalhos de Freire Filho (2010a; 2010b; 2011; 2012), que investiguei as representações de felicidade na publicidade nacional, por meio da análise de anúncios coletados nas revistas $O$ Cruzeiro e Veja no período de 1960 a $2010^{1}$.

Algumas premissas teóricas balizam 0 trabalho: além de conceber a publicidade como um objeto histórico, de acordo com Sant'anna (1997), compreendo as mensagens publicitárias como fenômenos culturais (Lears, 1994; Rocha, 1990; 2006). Outra premissa que ordena a pesquisa se vincula ao modo como nos posicionamos em relação à felicidade expressa nos anúncios publicitários. Constantemente, critica-se a publicidade por difundir uma visão simplória, enganosa, e até mesmo vazia da felicidade. Seja lá o que ela for, a vida feliz não está nos anúncios publicitários, nos avisam os críticos mais ferrenhos do consumismo posto em movimento pela maquinaria publicitária. Ainda que tal denúncia seja fundamental para combater a radical colonização dos modos de vida pelos desígnios mercantis, ela não possibilita refletir sobre 0 que a publicidade efetivamente nos diz sobre a felicidade. Desse modo, em vez de assumir as representações publicitárias como falsas, a pesquisa privilegiou a positividade dessas representações, no sentido foucaultiano do termo. Isto é, sua capacidade de tornar inteligível e manipulável uma certa realidade (Foucault, 1995).

0 que nos leva à última premissa teórica fundamental para o trabalho: a perspectiva de que a publicidade produz subjetividades ao, constantemente, formular e redefinir modelos de identificação que impõem guias e dão inteligibilidade ao cotidiano. Nesse sentido, as considerações de Rose (1999) sobre as tecnologias de consumo e o papel que elas possuem nos processos de produção de subjetividade na contemporaneidade são valiosos. Para 0 autor, a publicidade e as demais tecnologias de consumo conformariam "uma pluralidade de pedagogias para se viver uma vida que é tanto prazerosa quanto respeitável, pessoalmente única e socialmente normal. Elas oferecem 
novas formas para os indivíduos narrarem suas vidas [...]" (1999, p. 86). Sustento, portanto, que a publicidade exerce seu poder ao investir na condução da conduta do público, não somente nas suas escolhas de consumo, mas em uma dinâmica que se expande para outros terrenos como 0 casamento, a higiene, 0 cuidado com a saúde, as relações de trabalho, a criação dos filhos e, também, a conquista de uma vida feliz.

Neste artigo, apresento brevemente alguns momentos históricos em que a noção de felicidade assumiu diferentes contornos no discurso publicitário nacional e reflito sobre os modelos subjetivos que são estimulados a partir das formas de realização pessoal que a publicidade fornece em diferentes períodos como convenientes e desejáveis. Tais momentos não devem ser pensados como fases ou etapas, lineares e claramente definidas. Pelo contrário, os modos de representação da felicidade no discurso publicitário são marcados por rupturas, mas também por continuidades, as quais se estendem por várias décadas. Todavia, ao analisar o material coletado nas principais revistas semanais brasileiras, foi possível identificar particularidades e maneiras dominantes de apresentar a felicidade em diferentes períodos observados.

\section{A felicidade coletiva}

Felicidade, boa vida, bem viver, bem-estar, alegria, sorte, sucesso, realização, satisfação, plenitude, abundância, prosperidade... A constelação de termos que orbitam em um espaço próximo, mas nem sempre idêntico, pode ser expandida à exaustão. Bruckner (2010: 3) revela que Santo Agostinho foi capaz de encontrar exatamente 289 opiniões divergentes sobre o tema ainda em seu tempo. Ao observar os anúncios publicitários das décadas de 1960 e 1970, a pluralidade de maneiras de conceber o que torna uma vida significativa já se faz presente, porém uma das características peculiares do período é a ênfase encontrada nas peças publicitárias na dimensão coletiva da felicidade, principalmente no que concerne à satisfação pessoal resultante do pertencimento à família e à nação.

Nos anúncios dos anos 1960, a família possuía uma importância fundamental. Antes que os produtos fossem segmentados, era comum apresentar os bens de consumo indistintamente para todos os membros familiares, como 0 Óleo de Brilhantina da Colgate, que prometia, de uma só vez, "toda a família bem penteada" (O Cruzeiro, 13/02/1960, p. 38) e o Dauphine, "o carro da família" (O Cruzeiro, 19/01/1963, p. 58-59). Aos poucos, porém, os produtos foram individualizados. 0 rádio Phillips apresentava ilustrações de diversos modelos do eletrodoméstico, enquanto o texto afirmava: "falta um rádio em seu lar! (0 rádio só da mamãe). Claro que sim, pois as 'crianças' tomam conta do rádio para ouvir 'twist' e 'hully-gully' e ela perde os programas de que tanto gosta" (O Cruzeiro, 20/03/1965, p. 51). 
0 espaço doméstico não era, contudo, apenas

local de consumo coletivo e individual, era também a razão de se consumir as mercadorias anunciadas. 0 cumprimento de tarefas familiares era ligado aos produtos, enquanto 0 discurso publicitário reforçava os papéis sociais tradicionais destinados a cada membro da família. Dessa maneira, a Kombi Volkswagen lançava a provocação: "Prove à sua família que você gosta dela tanto quanto do trabalho", para, em seguida, sugerir que "uma família feliz compensa qualquer sacrifício" (O Cruzeiro, 19/08/1967, p. 131). Sob a pergunta "Você também não quer alegria?", 0 Jeep Rural Willys determinava: "Pense na família e responda por que não comprar agradáveis fins de semana, os mais alegres passeios", enquanto uma fotografia mostrava a família se divertindo na praia (O Cruzeiro, 14/04/1962, p. 77).

A família era acionada não só como domínio de afeto e diversão, mas também como um dever. A realização pessoal estava vinculada à manutenção de um cotidiano familiar harmônico e saudável, especialmente para a mulher, retratada nos anúncios como dona de casa. "A saúde da minha família depende de mim, por isso escolhi o novo Lifebuoy com Puralin”, garantia a mãe junto ao marido e seus filhos brincando, novamente, na praia (O Cruzeiro, 06/01/1962, p. 65). Já a protagonista de uma mensagem do sabão em pó Rinso confessava: "É uma satisfação para a esposa ver a camisa do marido assim tão branca", ao conversar com uma amiga, enquanto seus respectivos parceiros jogavam boliche despreocupados (O Cruzeiro, 19/01/1963, p.

75). A marca Lençóis Santistas era ainda mais enfática. À foto de uma mãe brincando com a filha na cama, seguia-se a afirmação de que "Ela é uma dona de casa feliz. Ela usa lençóis Santista. Feliz porque sabe cuidar bem da casa e da família" (O Cruzeiro, 11/05/1963, p. 89).

Em todos os exemplos, a felicidade é codificada da mesma forma, como uma submissão das vontades e escolhas individuais às necessidades familiares. Ser feliz é ter sucesso na realização do papel de dona de casa ou pai de família. A conquista da felicidade exige que o indivíduo canalize energias para assuntos que 0 ultrapassam. Os sujeitos delineados nos anúncios da década de 1960 encontravam a afirmação de sua importância no conformismo aos padrões estabelecidos coletivamente.

Com o início da ditadura militar, os anúncios publicitários investiram ainda mais na ideia de uma felicidade coletivamente nutrida, agora não só centrada na família, mas também na nação. 0 tom ufanista do período estimulou empresários e publicitários a se dirigir aos consumidores como brasileiros, os quais deveriam reunir esforços para garantir o progresso nacional. 0 mote do progresso e do crescimento do Brasil na propaganda durante o regime militar já foi analisado, principalmente, por um viés que pretendia comprovar as alianças entre o poder político então vigente e a indústria publicitária da época (Figueiredo, 
1998; Rocha, 2010). Interessa aqui ressaltar, entretanto, que o projeto de construção de uma potência nacional apresentado pela publicidade do período tomou ares de dever coletivo, que resultaria em um bem maior, a ser desfrutado por todos.

0 desenvolvimento econômico do Brasil era descrito como um processo que não só beneficiaria individualmente cada um e as suas famílias, mas todo o povo brasileiro, inclusive as futuras gerações. A publicidade já havia aprendido a eficácia de se dirigir ao público como você, mas neste período o pronome pessoal nós encontrou um prodigioso espaço no discurso publicitário. A primeira pessoa do plural era utilizada, a princípio, para que as empresas, muitas delas estrangeiras, se apresentassem ao público brasileiro, porém logo as mesmas empresas assumiam o papel de porta-vozes e representantes da população.

Durante 0 regime militar, as identidades oferecidas pelo discurso publicitário envolviam o estímulo à identificação dos indivíduos como membros de uma comunidade nacional, cujo projeto de desenvolvimento deveria ter a participação de todos. Em tais anúncios, era 0 esforço coletivo e não a mera iniciativa individual que se instigava. 0 Estado e as empresas privadas se colocavam como verdadeiros tutores do empreendimento nacional. Declarar confiança no país significava acenar a adesão a um projeto que, supostamente, orientava-se para o bem comum.
0 tom era ditado pelas propagandas

governamentais, como a que bradava em seu título "Noventa milhões continuam em ação", em razão da comemoração ao sesquicentenário da Independência do país. Abaixo de um mosaico de imagens de um jogador de futebol, de uma cirurgia médica em andamento, de trabalhadores do campo, da indústria, da construção civil e da educação, o texto prosseguia:

No campo e na cidade. Nas escolas e nos hospitais. Nas fábricas e nos escritórios. Nas minas e nos laboratórios. No mar das 200 milhas e nas estradas multiplicadas. Na arte e no esporte. A Independência é a soma de muitas vitórias. $\mathrm{Na}$ hora em que se comemoram os 150 anos do Brasil, vale a pena lembrar que este é um dos países que mais crescem no mundo. Com suor e fé, trabalho e união, orgulho e esperança (Veja, 12/07/1972, p. 6-7).

Como se pode notar, os ingredientes da receita governamental para a conquista do progresso se encontravam na coletividade, e não no simples esforço individual; no investimento no senso de pertença e na projeção de um futuro melhor para todos. Um discurso nacionalista que impunha aos indivíduos uma imagem de boa sociedade, na qual eles deveriam se engajar e adequar seus desejos e expectativas. Se pertencer a uma família sadia e contribuir de acordo com seu papel social para as tarefas familiares era uma garantia de assegurar a felicidade para os anúncios do período, outra forma de realização residia em fazer parte da conquista do bem-estar coletivo. Em ambos os casos, uma vida significativa envolvia o sacrifício pessoal em nome da felicidade de todos. 


\section{A felicidade exibida}

Nos anos 1960 e 1970, era a adesão a normas coletivas que garantia a felicidade, conforme o discurso publicitário, mas nem sempre a individualidade, necessariamente, precisava ser silenciada em nome da família ou da nação. Uma outra vertente da publicidade apostava que uma vida feliz significava a conquista de status diante dos outros. Junto aos anúncios que reforçavam os papéis familiares tradicionais e 0 discurso ufanista, somavam-se peças em que a competição social era abertamente instigada. Referências a geladeiras de "fazer inveja" (O Cruzeiro, 18/04/1964) e vinhos com "sabor de triunfo" (O Cruzeiro, 13/08/1960, p. 82) estimulavam 0 público a enxergar nas mercadorias marcadores classificatórios, a partir dos quais seria possível mensurar 0 grau de realização pessoal de cada um em comparação com os outros. 0 argumento era, todavia, muitas vezes, suavizado ou exposto de forma mais sutil, ainda que não menos impactante. Em um anúncio para os carros Dauphine, por exemplo, 0 ideal de competição é transmitido por meio de uma brincadeira de crianças. 0 anúncio apresenta dois garotos. Um deles, cabisbaixo, olha para o outro que, encostado no carro da marca, anuncia: " -0 nosso é mais bonito!", enquanto coloca a mão aberta próxima ao nariz, em um sinal de deboche para 0 amigo, cuja família teria um carro mais simples (O Cruzeiro, 09/03/1963, p. 66-67). 0 objetivo do anúncio não é infantilizar a competição social, mas amplificála e expandi-la para outros domínios. A posse e a exibição do automóvel garantem não apenas a realização pessoal do dono do carro, mas também uma afirmação da própria condição familiar. Não só indivíduos competem entre si por meio dos bens, mas também as suas famílias.

Quando os anúncios não abordam o consumo competitivo, fazem questão de simplesmente afirmar a existência de hierarquias sociais e assegurar que o produto posicione seus consumidores nos mais altos postos. Consumir é expressar pertença à elite em muitas mensagens comerciais, como a dos cigarros Luiz XV. 0 anúncio exibe uma ilustração que retrata uma mulher sofisticada, de vestido de festa, joias, luvas e piteira entre os dedos, em meio a um ambiente requintado, com quadros e mobília adornada. Um homem de terno e taça de vinho na mão se aproxima. 0 texto é apresentado com uma tipografia rebuscada, e garante que: "O estilo Luiz XV perdura através do tempo como símbolo de elegância. 0 mesmo apuro e bom gosto inspira aos fumantes exigentes a predileção pelos Cigarros Luiz XV, que aliam à qualidade requintada a lembrança de uma era de esplendor". Ao lado da imagem do produto, o slogan finaliza a mensagem: "Cigarros Luiz XV. 0 requinte de ontem para uma elite de hoje" (O Cruzeiro, 19/03/1960, p. 65). Muitos dos elementos do anúncio serão explorados com mais intensidade na próxima década: as referências à aristocracia, a classificação pelo gosto e a exibição de herança cultural como marca de distinção. Mas a mensagem central de afirmação 
da hierarquia social e da capacidade de os produtos refletirem o posicionamento de cada um nesse esquema classificatório já se apresenta totalmente formulada.

0 que está em jogo nesses anúncios é a contínua legitimação da estratificação social e a promessa de afirmação de pertencimento de classe por meio das mercadorias. Um tipo de apelo cuja presença não pode ser desvinculada do aprofundamento das desigualdades econômicas e sociais, o qual marca a sociedade brasileira do período. Mello e Novais (1998) descrevem o processo que instituiu no país 0 "capitalismo dos vencedores":

\begin{abstract}
A dinâmica econômica e social se apoiou continuamente, de um lado, na concorrência desregulada entre os trabalhadores, e, de outro, na monopolização das oportunidades de vida pelos situados no cimo da sociedade. Como resultado, em vez de a renda das grandes maiorias subir continuadamente em compasso com 0 aumento da produtividade social do trabalho [...], ocorre 0 contrário. Ou seja, os rendimentos dos trabalhadores subalternos são comprimidos para abrir espaço simultaneamente para lucros astronômicos e para a diferenciação de rendas e do consumo dos funcionários do dinheiro e da nova classe média (Mello e Novais, 1998, p. 618)
\end{abstract}

Outras mensagens preferem se dirigir àqueles que continuam disputando sua marcação social e não àqueles que alcançaram o "sucesso". Nesse caso, a metáfora da vida como uma escalada social, cujo maior valor reside em chegar ao topo, ganha primazia. A marca Ford, por exemplo, sugere no título de seu anúncio que "Quem tem Corcel é assim: nos últimos anos ele mudou de um apartamento para uma casa, mudou de posição, mudou de vida. Mas não mudou a marca do carro" (Veja, 12/05/1976, p. 55). A imagem que acompanha o texto é repetida em vários anúncios do período: 0 carro na entrada da garagem de uma grande casa. A única diferença é que, desta vez, o carro não está vazio. Seu dono está fechando a porta do automóvel, como se finalmente tivesse chegado ao cenário que ilustra a materialização de uma das formas de felicidade e sucesso do momento.

Neste contexto, a felicidade, em seu sentido de estado subjetivo, perde espaço para uma noção de boa vida organizada pelos bens de consumo, pelos quais os indivíduos podem compreender e classificar a si mesmos e os outros. Ter uma vida plena é se distinguir dos demais por meio das mercadorias e exibir tais diferenças. Ao estimular a distinção social, 0 discurso publicitário não só estipula um modo de socialização ideal, vinculado às mercadorias e a sua ostentação, mas também define, enfaticamente, o que torna a vida significativa. Se 0 sujeito se individualiza ao adentrar os estratos sociais mais rarefeitos, tornando-se alguém digno de reconhecimento e separandose do grupo, o que define bem viver não está aberto à discussão. Para 0 sujeito descrito nos anúncios do período, felicidade, realização pessoal e sucesso são conquistados não como experiências interiores e emocionais, mas, sim, como avaliações globais em relação à vida baseadas nos critérios de distinção social. 


\section{A felicidade autêntica}

Muitas continuidades podem ser percebidas entre 0 discurso publicitário dos anos 2000 e das décadas anteriores. No entanto, rupturas também podem ser encontradas. Uma das principais é que a publicidade contemporânea evita impor aos indivíduos regras exteriores que ditem como eles devem viver. "0 que vale a pena", aquilo que torna a vida significativa, a publicidade já não diz mais com tanta clareza como nas décadas anteriores. Algumas respostas chegam a ser ensaiadas: dedicar-se ao prazer, cuidar de si e da família, por exemplo. Mas o caminho mais comum tomado pelo discurso publicitário contemporâneo parece ser 0 de evitar qualquer posicionamento explicitamente normativo. Ao contrário, a propaganda enfatiza que as definições sobre 0 bem viver cabem exclusivamente aos indivíduos. Essa é a estratégia tomada por uma bem-sucedida campanha do grupo Pão de Açúcar, cujo slogan é uma simples, mas poderosa pergunta: "0 que faz você feliz?".

A marca, que se declara "Lugar de gente feliz", desenvolveu a questão de diversas maneiras ao longo dos últimos anos e, inclusive, ofereceu algumas possibilidades de resposta. Ao anunciar um concurso para eleger a melhor réplica para a questão, ela exibiu um homem brincando com frutas em forma de um automóvel e aludiu à possibilidade de que as viagens podem ser sinônimo de felicidade (Veja, 15/08/2007, p. 83). Para o Dia dos Namorados, o grupo alterou a pergunta para "0 que faz seu amor feliz?" e mostrou um casal bebendo vinho e trocando carinhos no chão da sala de estar, em um momento íntimo (Veja, 13/06/2007, p. 73). No período natalino, a empresa novamente adaptou a questão para "0 que faz seu natal feliz?" e escolheu como significado de felicidade uma criança que descobre seu presente na manhã de Natal (Veja, 12/12/2007, p. 125). Independentemente dos diversos desenvolvimentos da campanha e das possíveis respostas que os anúncios sugerem, a existência da própria pergunta é significativa e permite a elaboração de algumas observações.

Questionar os consumidores sobre o que torna a vida feliz significa ao mesmo tempo admitir que os critérios que definem a felicidade não podem ser objetivamente articulados, que eles não se encontram necessariamente no cumprimento dos deveres familiares, na distinção social, no pertencimento à nação, no sucesso profissional, na realização amorosa ou em qualquer outra forma fixa e estável de definir a boa vida. Cada um dos feitos listados pode significar um modo de viver significativo, porém em si mesmos eles são apenas opções múltiplas de estilos de vida. Perguntar o que traz felicidade ao indivíduo é, consequentemente, afirmar que apenas ele pode escolher o que o faz feliz.

Uma possível razão por que a pergunta não foi formulada nas décadas anteriores é que, apesar de existirem, então, projetos concorrentes de felicidade, eles não eram apresentados aos indivíduos como escolhas. Ao contrário, 
as definições de boa vida eram impostas aos indivíduos, os quais deveriam incorporar ou não modelos de felicidade preestabelecidos, cujas justificativas não se encontravam nas preferências individuais de cada um, mas nas expectativas e convenções socialmente partilhadas. Ver o marido ser bem-sucedido no trabalho poderia ser uma definição de felicidade feminina nos anos 1960, não porque a esposa assim escolheu ser feliz, mas porque a sociedade esperava que 0 papel feminino fosse ajudar o marido em sua carreira. A felicidade se ligava, portanto, pelo menos em parte, à capacidade de corresponder às expectativas sociais e não apenas a um impulso individual.

A formulação da pergunta demonstra ainda 0 deslocamento dos critérios de julgamento e das fontes morais para 0 interior dos indivíduos: os anúncios do Pão de Açúcar colocam sob única responsabilidade do indivíduo definir a boa vida. Todavia, nenhum parâmetro exterior é dado. Cabe ao próprio sujeito descobrir qual é a sua concepção de vida feliz. Se a pergunta significa, portanto, um alargamento dos modos de conduta considerados desejáveis, ela subentende outra obrigação: ser feliz (Freire Filho, 2010). Afinal, uma vez que o próprio indivíduo pode determinar o que significa 0 bem viver, caso ele fracasse, não poderá culpar nenhuma exigência que contraria seus interesses e inclinações.

A individualização dos critérios para os juízos de valor surge em diversos outros anúncios do período contemporâneo. Nessas mensagens, ideais antes considerados relativamente estáveis são expostos como interpretações individuais de marcadores de sentido, sendo que a única obrigação que a publicidade faz é que os sujeitos sejam fiéis às suas próprias concepções de beleza, amor, bem-estar, etc. Um exemplo é a mensagem dos produtos de beleza Nivea. 0 anúncio é um sequencial, composto por seis páginas. A primeira página dupla mostra uma jovem loira de babydoll, rosa e justo, sentada na beirada da cama desfeita, em um quarto banhado pela luz do sol. A protagonista exibe um sorriso tímido, enquanto leva uma das mãos à boca, em um gesto mais ingênuo do que insinuante. A foto carrega a logo da marca e a declaração de que "Beleza é gostar de si mesma”. A página dupla seguinte é uma foto em plano fechado de uma mulher morena abraçada a dois amigos. Ela troca sorrisos com a amiga, o que contextualiza a frase que acompanha a imagem: "Beleza é ter alto astral". A última foto do anúncio é composta novamente por uma fotografia em plano fechado. Dessa vez, de um casal trocando carícias na cama. 0 homem, sem camisa, beija a orelha da mulher, que sorri de olhos fechados. 0 título afirma que "Beleza é Nivea", mas o encerramento da peça traz ainda 0 seguinte texto:

Beleza. É mais do que a busca pela perfeição. É mais do que uma imagem. É parte de cada um de nós. E está presente em tudo que nos cerca. Muitas vezes, está bem à nossa vista. Outras vezes, ela vem de dentro de nós. É a única coisa que podemos ver com os olhos. E também sentir com o coração. Não há ninguém que possa realmente defini-la. Porque a beleza é tão 
particular, valiosa e cheia de nuances como a própria vida. É assim que a beleza é Nivea. (Veja, 05/03/2008, p. 66-71).

A concorrente Natura também exemplifica a forma como os valores são relativizados, e os critérios de julgamento são deslocados para o interior dos indivíduos no discurso publicitário atual. Em dois anúncios veiculados em datas próximas, a marca questiona a existência de uma noção fixa para a ideia de bem-estar, oferecendo suas próprias definições. Um dos anúncios traz duas fotos de Luiza Pasqualini, identificada como uma consultora de vendas da Natura, de 39 anos. A primeira foto traz um close da protagonista aplicando rímel em seus cílios, junto à inscrição "Bem-estar é aprender a valorizar a sua própria beleza". A segunda foto mostra a consultora maquiando uma de suas clientes, acompanhada do texto: "Estar bem é ensinar uma nova cliente a gostar ainda mais de si mesma”. A última página do anúncio traz informações factuais sobre 0 trabalho das consultoras da marca (Veja, 16/06/2004, p. 18-20).

Além da temática e da abordagem semelhantes, os anúncios ainda possuem algumas convergências. 0 primeiro ponto em comum é a maneira como as noções de beleza e bem-estar são consideradas, a princípio, basicamente significantes vazios e flutuantes à espera de infinitas interpretações. Beleza e bem-estar não são tratados como conceitos fixos, valores que servem para julgar o belo e o confortável, mas termos que só se tornarão significativos a partir do momento em que alguém for capaz de ancorar as noções a partir de suas experiências e inclinações pessoais. A segunda característica partilhada pelos anúncios diz respeito às referências à autenticidade. Uma das características singulares dos anúncios dos anos 2000 é a valorização da individualidade de cada consumidor em relação às exigências sociais. Cada um deve buscar seu próprio sentido de beleza, bem-estar e felicidade, porque somente sendo verdadeiro consigo mesmo é que a realização pessoal pode ser conquistada. Essa é a noção central também daquilo que Taylor (2007) chama de individualismo expressivista, o qual organizaria a moralidade contemporânea. Dois anúncios para os cigarros Free - cujo slogan, "Cada um na sua, mas com uma coisa em comum", serviria perfeitamente de mote para o expressivismo descrito por Taylor - ilustram a desarticulação no discurso publicitário dos critérios que regem a boa vida.

Em uma dessas peças, composta por duas páginas, vemos duas fotos. A primeira é a imagem de uma mulher jovem, de longos cabelos negros, que sorri levando as mãos à boca, em um gesto infantilizado, com uma expressão típica de uma criança que "fez arte", mas não se importa com isso. Sua foto é acompanhada de uma etiqueta que traz dados pessoais da protagonista preenchidos à mão. A etiqueta traz o nome da personagem, "Adriana Rechi", seu sexo, sua idade, 27 anos, atividade, "agitadora cultural", além da pergunta "Qual é a sua?", cuja resposta é "Sou um animal completamente emocional". A página ao lado é ilustrada com a foto da protagonista de pé, sorrindo, enquanto tenta se apoiar ou dançar nas 
nádegas do companheiro, que está deitado na cama junto ao chão, apenas de calça jeans (Veja, 12/07/2000, p. 2-3).

0 outro anúncio possui uma estrutura semelhante, no entanto, agora o protagonista é um jovem. Em uma das páginas, vemos o rapaz sorrindo, sendo abraçado pela namorada. A etiqueta é preenchida: Rafael Perez, 25 anos, cenógrafo. A pergunta "Qual é a sua?" ganha a seguinte resposta: "Ser feliz é não ter tempo para ser infeliz". A página ao lado traz mais duas fotos: uma mostra detalhes do rosto do protagonista, em plano fechado, em um ângulo diagonal, arrojado. A outra fotografia é composta pelo rapaz olhando para cima, de mãos abertas, na calçada de rua, como se estivesse conversando com alguém em uma janela de um prédio, em um momento casual, não posado (Veja, 08/11/2000, p. 2-3).

Ambos os anúncios retratam os personagens em momentos íntimos e descontraídos, distantes do convívio social. Os dois protagonistas têm inclinações artísticas - agitadora cultural e cenógrafo. Finalmente, os dois enfatizam a importância das emoções nos seus projetos de vida. A jovem salienta que a emoção é como um caráter constitutivo de sua personalidade, enquanto 0 rapaz admite a obrigação de ser feliz como objetivo de vida. A própria pergunta "Qual é a sua?" também é significativa, pois, assim como a questão colocada pelos anúncios do grupo Pão de Açúcar, deixa sob responsabilidade única e exclusiva dos próprios indivíduos a definição do que é valioso na vida de cada um. Se os anúncios para os cigarros Free demonstram a desarticulação da boa vida, a maneira como a publicidade deixa de impor um modo de vida específico para prescrever e exigir que cada um defina seus projetos de vida de acordo com a sua essência.

\section{Observações finais}

Uma chave para interpretar as transformações nos modos de representar a felicidade na publicidade nacional pode ser encontrada nas observações de MacIntyre (2007), a respeito das transformações nas formas de julgamento moral na modernidade. Segundo o filósofo britânico, uma característica fundamental dos dilemas morais contemporâneos é a ausência de critérios racionais para a articulação dos argumentos. As atuais definições do que constitui 0 bem, 0 certo, o justo se tornaram completamente dependentes das preferências e atitudes individuais. Desse modo, para 0 autor, os dilemas morais hodiernos são codificados, desenvolvidos e interpretados como simples disputas entre vontades antagônicas. Se antes a honra, a religião, o dever e os compromissos comunais serviam de fontes morais e parâmetros para avaliar e ordenar, objetivamente, valores e ações, MacIntyre (2007) observa agora uma multiplicação de fontes morais, o que 0 autor nomeia de emotivismo:

0 emotivismo é uma doutrina em que todos os juízos avaliativos e, mais especificamente, todos os julgamentos morais não são nada além do que expressões de preferência, expressões 
de atitude ou sentimento, na medida em que eles são morais ou avaliativos em caráter. (Maclntyre, 2007, p. 12).

Para o filósofo britânico, o emotivismo corresponde a um empobrecimento e um declínio da moral, uma vez que se sustenta por meio da defesa da impossibilidade de articulação de um padrão objetivo e impessoal para as justificativas morais: "Cada indivíduo, implícita ou explicitamente, deve adotar seus próprios princípios com base em suas escolhas" (MacIntyre, 2007: 20). Assim, surge o eu emotivista. Um self que, destituído de critérios exteriores, define-se a si próprio e se caracteriza por uma recusa das convenções sociais. Para o eu emotivista, "o mundo social não é nada além do que um lugar de encontro para vontades individuais", uma compreensão do mundo que resume a esfera social a "uma arena para a conquista da sua própria satisfação". Estabelecese, então, um modelo subjetivo que interpreta a realidade como "uma série de oportunidades para a própria diversão, cujo maior inimigo é o tédio" (MacIntyre, 2007: 25). 0 eu emotivista se separa dos papéis que representa socialmente, ansioso por se despir das identidades sociais que sufocam o seu verdadeiro eu. Um self que se afirma por escolhas individuais arbitrárias e soberanas, haja vista que as fronteiras tradicionais que limitavam a vida humana a determinados fins são colocadas em xeque na modernidade.

Autores como Rieff (1987) e Lipovetsky (2007) antecipam ou confirmam, a partir de diferentes perspectivas, as críticas de MacIntyre (2007) à moralidade contemporânea. Rieff (1987) descreve a emergência da cultura terapêutica, a qual, de modo semelhante ao emotivismo, colocaria o bemestar individual acima dos interesses comunais e produziria um modelo subjetivo autocentrado, hiperpsicologizado, despido de compromissos superiores e cuja única obrigação residiria em canalizar esforços para a autorrealização pessoal. Lipovetsky (2007), por sua vez, sublinha a derrocada da moralidade tradicional na contemporaneidade, enfatizando sua substituição por um posicionamento pós-moralista, esvaziado de conteúdo ético, em que compromissos e exigências se tornam opcionais, seletivos.

As transformações morais e culturais traçadas por esses autores possuem raízes e consequências múltiplas. Certamente, não se pode atribuir exclusivamente aos publicitários nacionais o poder de originar mudanças nas formas de compreensão pessoal e coletiva. Porém, diante do quadro teórico traçado pelos autores, é possível perceber como a publicidade nacional após os anos 1980, e especialmente a partir da década seguinte, não só incorpora o ideário do emotivismo aos seus argumentos de venda, como, ativamente, promove e celebra novos modelos subjetivos, em que o self se autonomiza das expectativas sociais, antes colocadas sobre si, e transforma a realização pessoal em fim último. A perda de fôlego dos projetos coletivos nacionais e a relativização do individualismo materialista resultam no fortalecimento de uma nova forma 
de individualismo, que aposta na expressão das singularidades e inclinações pessoais de cada consumidor. Nesse sentido, a publicidade passa a se abster de definir o que constitui a boa vida, deixando tal tarefa a cargo de cada um, ao mesmo tempo em que as mercadorias começam a ser apresentadas como ferramentas para autoexpressão e não apenas marcadores de classe.

Comparada a versões anteriores do discurso publicitário, as quais vinculavam a realização pessoal à submissão ao bem-estar do outro, ou então instauravam uma tirania de exibição materialista, a propaganda recente pode parecer mais inclusiva, mais compreensiva ou mais igualitária. Entretanto, definitivamente, não é menos nociva. A expansão do eu na publicidade brasileira alimenta um ímpeto ferrenho de autogratificação, que submete todo e qualquer investimento individual à promessa de recompensa em benefício próprio. A publicidade contemporânea contribui ainda para a desorientação que leva os indivíduos ao narcisismo, ao mesmo tempo em que promete resolvê-la. Ela mina os marcadores de sentido tradicionais e desarticula juízos de valor para localizar o próprio indivíduo como única fonte de referência, assistindo-0 com as mercadorias anunciadas para expressar sua suposta autenticidade.

Ser fiel a si mesmo, porém, é tanto um gesto libertador das amarras sociais quanto uma nova forma de gerar angústia e ansiedade. Pois a autenticidade que a propaganda promove possui tanto afinidades com a sua origem romântica quanto dissonâncias. A recusa das expectativas sociais privilegia agora um eu que escolhe, sem limites, no mundo dos bens. E o verdadeiro eu é menos resultante do incentivo à autodescoberta do que o constante desempenho de si mesmo. A publicidade contemporânea exige principalmente a performance da autenticidade (Freire Filho, 2012): que os indivíduos exibam, por meio de suas práticas de consumo, seus verdadeiros eus. Um self autêntico que pode ser, por sua vez, objeto de constantes melhorias, transformações, investimentos, ajustes e adequações. Se a publicidade convidava os indivíduos ao autoescrutínio a partir de critérios e padrões de beleza, aparência e sucesso exteriores, 0 que ela fez foi deslocar tais critérios para a responsabilidade dos próprios indivíduos.

\section{Referências}

BRUCKNER, Pascal. Perpetual euphoria: on the duty to be happy. Princeton: Princeton University Press, 2010. FIGUEIRED0, Anna Cristina Camargo Moraes.

"Liberdade é uma calça velha, azul e desbotada": publicidade, cultura de consumo e comportamento político no Brasil, 1954-1964. São Paulo: Hucitec, 1998. FOUCAULT, Michel. 0 sujeito e o poder. In: DREYFUS, Hubert; RABINOW, Paul. Michel Foucault. Uma trajetória filosófica. Para além do estruturalismo e da hermenêutica, p. 231-249. Rio de Janeiro: Forense Universitária, 1995.

FREIRE FILHO, João. Fazendo pessoas felizes: o poder moral dos relatos midiáticos. In: Anais do XIX Encontro da Associação Nacional dos Programas de Pós-Graduação em Comunicação. Rio de Janeiro: Compós, 2010a. 
(org.). Ser Feliz Hoje: reflexões sobre 0 imperativo de felicidade. Rio de Janeiro: FGV, 2010b.

Existir aos olhos dos outros: reality shows, as aventuras autênticas de indivíduos em busca de reconhecimento. In: FREIRE FILHO, João; BORGES, Gabriela. (org.). Estudos de televisão: diálogos BrasilPortugal, p. 115-148. Porto Alegre: Sulina, 2011. Big Brother Brasil e o valor da autenticidade. In: FRANÇA, Vera; CORRÊA, Laura. (orgs.). Mídia, instituições e valores, p. 53-66. Belo Horizonte: Autêntica, 2012.

LEARS, T.J. Jackson. Fables of abundance: a cultural history of advertising in America. Nova Iorque: Basic Books, 1994.

LIPOVETSKY, Gilles. A felicidade paradoxal. São Paulo: Companhia das Letras, 2007.

MACINTYRE, Alastair. After virtue: a study in moral theory. Notre Dame: University of Notre Dame Press, 2007.

MAZETTI, Henrique. As marcas da felicidade: transformações do bem viver na publicidade brasileira (1960-2010). 2014. 247 p. Tese (Doutorado em Comunicação e Cultura) - Escola de Comunicação, Universidade Federal do Rio de Janeiro, Rio de Janeiro, 2014.

MELLO, João Manuel Cardoso; NOVAIS, Fernando. Capitalismo tardio e sociabilidade moderna. In: SCHWARCZ, Lílian. (org.). História da vida privada no Brasil: contrastes da intimidade, v.4, p. 559-658. São Paulo: Cia das Letras, 1998.

RIEFF, Philip. 0 triunfo da terapêutica. São Paulo: Brasiliense, 1987.

ROCHA, Everardo. Magia e capitalismo: um estudo antropológico da publicidade. São Paulo: Brasiliense, 1990. Representações do Consumo: estudos sobre a narrativa publicitária. Rio de Janeiro: PUC-Rio/ Mauad, 2006.
ROCHA, Maria Eduarda da Mota. A nova retórica do capital: a publicidade brasileira em tempos neoliberais. São Paulo: Edusp, 2010.

ROSE, Nikolas. Powers of freedom: reframing political thought. Cambrigde: Cambridge University Press, 1999.

SANT'ANNA, Denise B. Propaganda e História: antigos problemas, novas questões. Projeto História, n. 14, p. 89-112, 1997. . Uma história da construção do direito à felicidade no Brasil. In: FREIRE FILHO, João (org.). Ser feliz hoje: reflexões sobre o imperativo da felicidade. Rio de Janeiro: FGV, 2010.

TAYLOR, Charles. As fontes do self: a construção da identidade moderna. São Paulo: Loyola, 2005. 


\section{A brief history of happiness in} national advertising (1960-2010)

\section{Una breve historia de la felicidad en} la publicidad nacional (1960-2010)

\section{Abstract}

The article aims to present and discuss changes in representations of happiness in the advertisements published in magazines Veja and O Cruzeiro between 1960 and 2010, in order to reflect on the moral values that informed the national advertising discourse. We identify three moments that mark different ways to represent happiness in the ads: 1) an association of the happy life to the collective experience of family or nation; 2) the narrowing between happiness and to the notion social status; 3 ) the sedimentation of relations between happiness and self-expression. Finally, these changes are interpreted from works of author as MacIntyre, Taylor and Lipovetsky.

\section{Keywords}

Advertising. Happiness. Morality.

\section{Resumen}

El artículo tiene como objetivo presentar y discutir los cambios en las representaciones de la felicidad en los anuncios publicados en las revistas Veja y 0 Cruzeiro en el período de 1960 y 2010, con el fin de reflexionar sobre los valores morales que informan al discurso publicitario nacional. Identificamos tres momentos distintos que marcan diferentes formas de representar la felicidad en los anuncios: 1) una asociación de la vida feliz con la experiencia colectiva de la familia o nación; 2) el estrechamiento de la vida plena con el status social; 3) el establecimiento de relaciones entre la felicidad y la auto-expresión. Por último, estos cambios son interpretados con la ayuda de trabajos de autores como MacIntyre, Taylor y Lipovetsky.

\section{Palabras clave}

Publicidad . Felicidad. Moralidad. 


\section{Expediente}

A revista E-Compós é a publicação científica em formato eletrônico da Associação Nacional dos Programas de Pós-Graduação em Comunicação (Compós). Lançada em 2004, tem como principal finalidade difundir a produção acadêmica de pesquisadores da área de Comunicação, inseridos em instituições do Brasil e do exterior.

\section{E-COMPÓS I www.e-compos.org.br I E-ISSN 1808-2599}

Revista da Associação Nacional dos Programas de Pós-Graduação em Comunicação.

Brasília, v.19, n.3, set./dez. 2016.

A identificação das edições, a partir de 2008, passa a ser volume anual com três números.

Indexada por Latindex I www.latindex.unam.mx

\section{CONSELHO EDITORIAL}

Alexandre Farbiarz, Universidade Federal Fluminense, Brasil Alexandre Rocha da Silva, Universidade Federal do Rio Grande do Sul, Brasil Ana Carolina Escosteguy, Pontifícia Universidade Católica do Rio Grande do Sul, Brasil Ana Carolina Rocha Pessôa Temer, Universidade Federal de Goiás, Brasil Ana Regina Barros Rego Leal, Universidade Federal do Piauí, Brasil Andrea França, Pontifícia Universidade Católica do Rio de Janeiro, Brasil André Luiz Martins Lemos, Universidade Federal da Bahia, Brasil Antonio Carlos Hohlfeldt, Pontifícia Universidade Católica do Rio Grande do Sul, Brasil Arthur Ituassu, Pontifícia Universidade Católica do Rio de Janeiro, Brasil Álvaro Larangeira, Universidade Tuiuti do Paraná, Brasil Ângela Freire Prysthon, Universidade Federal de Pernambuco, Brasil César Geraldo Guimarães, Universidade Federal de Minas Gerais, Brasil Cláudio Novaes Pinto Coelho, Faculdade Cásper Líbero, Brasil Daisi Irmgard Vogel, Universidade Federal de Santa Catarina, Brasil Denize Correa Araujo, Universidade Tuiuti do Paraná, Brasil

Eduardo Antonio de Jesus, Pontifícia Universidade Católica de Minas Gerais, Brasil Daniela Zanetti, Universidade Federal do Espirito Santo, Brasil

Eduardo Vicente, Universidade de São Paulo, Brasil

Elizabeth Moraes Gonçalves, Universidade Metodista de São Paulo, Brasil Erick Felinto de Oliveira, Universidade do Estado do Rio de Janeiro, Brasil Francisco Elinaldo Teixeira, Universidade Estadual de Campinas, Brasil Francisco Paulo Jamil Almeida Marques, Universidade Federal do Paraná, Brasil Gabriela Reinaldo, Universidade Federal do Ceará, Brasil

Goiamérico Felício Carneiro Santos, Universidade Federal de Goiás, Brasil Gustavo Daudt Fischer, Universidade do Vale do Rio dos Sinos, Brasil Herom Vargas, Universidade Municipal de São Caetano do Sul, Brasil Itania Maria Mota Gomes, Universidade Federal da Bahia, Brasil Janice Caiafa, Universidade Federal do Rio de Janeiro, Brasil Jiani Adriana Bonin, Universidade do Vale do Rio dos Sinos, Brasil
José Afonso da Silva Junior, Universidade Federal de Pernambuco, Brasil José Luiz Aidar Prado, Pontifícia Universidade Católica de São Paulo, Brasil Juçara Gorski Brittes, Universidade Federal de Ouro Preto, Brasil Kati Caetano, Universidade Tuiuti do Paraná, Brasil Lilian Cristina Monteiro França, Universidade Federal de Sergipe, Brasil Liziane Soares Guazina, Universidade de Brasilia, Brasil Luíza Mônica Assis da Silva, Universidade de Caxias do Sul, Brasil Luciana Miranda Costa, Universidade Federal do Pará, Brasil Malena Segura Contrera, Universidade Paulista, Brasil Monica Martinez, Universidade de Sorocaba, Brasi Maria Ataide Malcher, Universidade Federal do Pará, Brasil Marcia Tondato, Escola Superior de Propaganda e Marketing, Brasil Marcel Vieira Barreto Silva, Universidade Federal da Paraíba, Brasil Maria Clotilde Perez Rodrigues, Universidade de São Paulo, Brasil Maria das Graças Pinto Coelho, Universidade Federal do Rio Grande do Norte, Brasil Mauricio Ribeiro da Silva, Universidade Paulista, Brasil

Mauro de Souza Ventura, Universidade Estadual Paulista, Brasil Márcio Souza Gonçalves, Universidade do Estado do Rio de Janeiro, Brasil Micael Maiolino Herschmann, Universidade Federal do Rio de Janeiro, Brasil Mirna Feitoza Pereira, Universidade Federal do Amazonas, Brasil Nísia Martins Rosario, Universidade Federal do Rio Grande do Sul, Brasil Potiguara Mendes Silveira Jr, Universidade Federal de Juiz de Fora, Brasil Regiane Regina Ribeiro, Universidade Federal do Paraná, Brasil Rogério Ferraraz, Universidade Anhembi Morumbi, Brasil Rose Melo Rocha, Escola Superior de Propaganda e Marketing, Brasil Rozinaldo Antonio Miani, Universidade Estadual de Londrina, Brasil Sérgio Luiz Gadini, Universidade Estadual de Ponta Grossa, Brasil Simone Maria Andrade Pereira de Sá, Universidade Federal Fluminense, Brasil Veneza Mayora Ronsini, Universidade Federal de Santa Maria, Brasil Walmir Albuquerque Barbosa, Universidade Federal do Amazonas, Brasil

\section{CONSELHO CIENTÍFICO}

Cristiane Freitas Guttreind, Pontifícia Universidade Católica do Rio Grande do Sul, Brasil Eduardo Morettin, Universidade de São Paulo, Brasil Felipe Costa Trotta, Universidade Federal Fluminense, Brasil Irene de Araújo Machado, Universidade de São Paulo, Brasil

\section{COMISSÃO EDITORIAL}

Eduardo Antonio de Jesus, Pontifícia Universidade Católica de Minas Gerais, Brasil Osmar Gonçalves dos Reis Filho, Universidade Federal do Ceará, Brasil

\section{CONSULTORES AD HOC}

Geane C. Alzamora, Universidade Federal de Minas Gerais, Brasil Teresinha Cruz Pires, Pontifícia Universidade Católica de Minas Gerais, Brasil

\section{EQUIPE TÉCNICA}

ASSISTENTE EDITORIAL Márcio Zanetti Negrini

REVISÃO DE TEXTOS Press Revisão

EDITORAÇÃO ELETRÔNICA Roka Estúdio

IMAGEM DE CAPA Silas de Paula

\section{COMPÓS I www.compos.org.br}

Associação Nacional dos Programas de Pós-Graduação em Comunicação

Presidente

Edson Fernando Dalmonte

Programa de Pós-Graduação em Comunicação

e Cultura Contemporânea - UFBA

edsondalmonte@uol.com.br

Vice-presidente

Cristiane Freitas Gutfreind

Programa de Pós-Graduação em Comunicação Social - PUC-RS cristianefreitas@pucrs.br

Secretário-Geral

Rogério Ferraraz

Programa de Pós-Graduação em Comunicação

Universidade Anhembi Morumbi

rogerioferraraz@anhembimorumbi.edu.br

CONTATO I revistaecompos@gmail.com 